\title{
DIÁSPORAS E APROXIMAÇÕES ENTRE EDUCAÇÃO SEXUAL NAS SÉRIES INICIAIS E ENFRENTAMENTO AO PRECONCEITO: DISCUSSÕES SOBRE A LEI MUNICIPAL "ESCOLA SEM HOMOFOBIA" DE MARINGÁ
}

\author{
DIÁSPORAS Y APROXIMACIONES ENTRE EDUCACIÓN SEXUAL EN LOS \\ AÑOS INICIALES Y ENFRENTAMIENTO AL PREJUICIO: DISCUSIONES \\ SOBRE LA LEY MUNICIPAL “ESCUELA SIN HOMOFOBIA” DE MARINGÁ
}

\author{
DIASPORAS AND APPROACHES BETWEEN SEX EDUCATION IN THE \\ INITIAL SERIES AND CONFRONTATION TO THE PREJUDICE: \\ DISCUSSIONS ON THE MUNICIPAL LAW" "SCHOOL WITHOUT \\ HOMOPHOBIA" OF MARINGÁ
}

\author{
Franciele Monique Scopetc dos SANTOS $^{1}$ \\ Ana Cláudia Bortolozzi MAIA ${ }^{2}$
}

RESUMO: Essa discussão se efetiva na construção histórica do projeto de lei $\mathrm{n}^{\circ}$ 8.728/2010 no município de Maringá, Paraná, que consolidou o destino de verbas específicas à formação continuada das professoras (es) da rede municipal de ensino e possibilitou o primeiro programa municipal (do Brasil) de combate a homofobia na educação básica (primeiras séries da formação escolar). Ressaltamos que a lei $\mathrm{n}^{\mathrm{o}}$ 11.695/2010 alterou a lei no 8.728/2010 que dispõe da criação do Programa Escola Sem Homofobia. Sendo assim, essa proposta de análise vigora sobre o plano discursivo e descritivo do processo de formação e votação da lei, que a partir da literatura consultada, seria a única lei municipal no Brasil que promove um projeto vinculado ao combate à homofobia na rede municipal de ensino. Assim como ressaltarmos os aspectos reflexivos sobre a educação sexual nas séries iniciais.

PALAVRAS-CHAVE: Lei. Homofobia. Movimento social. Educação básica. Séries iniciais. Educação sexual.

RESUMEN: Esa discusión se centra en la construcción histórica del proyecto de Ley $n^{o}$ 8.728/2010 en el municipio de Maringá, Paraná, que consolidó el destino del presupuesto específico a la formación continua de los(las) profesores(as) de la red de municipios de enseñanza y posibilitó el primer programa municipal (de Brasil) de combate a la homofobia en la educación básica (primeros años de la formación escolar). Destacamos que la Ley $n^{\circ} 11.695 / 2010$ alteró la Ley $n^{o}$ 8.728/2010, que dispone sobre la creación del Programa Escuela Sin Homofobia. Así, esa propuesta de análisis enfoca el plano discursivo y descriptivo del proceso de formación y votación de la ley, que desde la literatura consultada, sería la única ley de una ciudad en Brasil que promueve un proyecto vinculado al combate a la homofobia en la red de municipios de

\footnotetext{
1 Doutoranda no programa de Pós-graduação em Educação Escolar, linha de pesquisa: Sexualidade, Cultura e Educação Sexual -Fclar/UNESP/Araraquara - franmonique@ gmail.com.

${ }^{2}$ Professora do Departamento de Psicologia Fc/UNESP/Bauru - aclaudia@ fc.unesp.br.
} 
enseñanza. También destacamos los aspectos reflexivos sobre la educación sexual en los años iniciales.

PALABRAS CLAVE: Ley. Homofobia. Movimiento social. Educación básica. Años iniciales. Educación sexual.

ABSTRACT: This discussion is effective in the historical construction of the law No. 8728/2010 in Maringá, Paraná, which consolidated the fate of specific funds to the continuing education of teachers(es) of the municipal education system and allowed the first municipal program (the Brazil) to combat homophobia in basic education (early grades of schooling). We stress that Law n. 11,695 / 2010 has changed the law $n$. 8728/2010 of the creation the disposition to "School without Homophobia" Program. Therefore, this proposed force analysis on the discursive and descriptive plan of the training process and vote on the legislation, which from the literature, would be the only municipal law in Brazil that promotes linked to combat homophobia in the municipal project education. Like, emphasizes reflective aspects of sex education in the early grades.

KEYWORDS: Law. Homofobia. Social movement. Basic education. Initial series. Sexual Education.

\section{Introdução}

Uma década depois da criação do Plano Nacional Brasil sem Homofobia (2004), ainda somos um Estado de quase (ou parcial) direitos no que concerne à cidadania plena de Lésbicas, Gays, Bissexuais, Travestis e Transexuais (LGBT) ${ }^{3}$. É notória a trajetória dos movimentos sociais organizados pela livre expressão da diversidade sexual e identidade de gênero no Brasil (FACCHINI, 2005), porém ainda sofremos com os constantes ataques à dignidade e direitos quando pensamos no campo da execução e consolidação de políticas públicas que atendem demandas da aqui entendida minoria. Nesse sentido, essa análise parte do macro-marco institucional e político do Plano Nacional Brasil sem Homofobia (BSH) (2004) para chegarmos a um micro-marco institucional e político que foi a lei $\mathrm{n}^{\circ} 8.728 / 2010$ no município de Maringá, Paraná, única lei municipal dentre os mais de cinco mil municípios em nosso país, que visa combater no âmbito educacional a les/homo/trans/bi fobias, o sexismo, desigualdade de gênero e o machismo na rede municipal de ensino, nas séries iniciais da

\footnotetext{
${ }^{3}$ Baseamos nossa afirmação no que tange aos constantes ataques fundamentalistas aos avanços políticos e institucionais das demandas pleiteadas pelo movimento social organizado de Lésbicas, Gays, Bissexuais, Travestis e Transexuais. A título exemplificativo; pontuamos o embargo ideológico ao projeto Escola sem Homofobia ou o caluniado "kit gay", e, sobretudo, a paliativa e não constitucional, medida que resguarda o casamento igualitário, oriunda do Conselho Nacional de Justiça (CNJ).
} 
educação escolar. Para então promovermos um debate no que concerne à educação sexual na infância e seus reflexos na produção acadêmica no Brasil, entendemos que o princípio que move a educação sexual escolar, a saber:

“[...] educação sexual na escola deve ser um processo intencional, planejado e organizado que vise proporcionar ao aluno uma formação que envolva conhecimento, reflexão e questionamento; mudança de atitudes, concepções e valores; produção e desenvolvimento de uma cidadania ativa; e instrumentalização para o combate à homofobia e à discriminação de gênero" (MAIA; RIBEIRO, 2011, p. 77).

Importante destacar no texto o que nos viabiliza como responsabilidade da educação sexual, feita de modo objetivo e programada, que é agir no combate a elementos de preconceito social e violência. A educação sexual possui um caráter ético e propulsor de uma reflexão cidadã: é a partir dessa compreensão que pensamos na educação sexual, seja ela nas séries iniciais ou finais da educação básica.

Ao pensarmos o macro-marco institucional e político do $\mathrm{BSH}$ é necessário levantarmos como ele se tornou um referencial, sendo assim, como foi a partir da leitura e debate no movimento social municipal de Maringá que o programa lançou luzes à formulação da lei, objeto central desta análise. Cabe aqui ressaltarmos que toda articulação e proposição da lei deram-se no âmbito do debate articulado com a vereadora e vereadores, então atuantes na décima quarta legislatura do município ${ }^{4}$. Não é surpreendente que apenas uma mulher tenha legislado na Casa municipal dentre o período compreendido aqui de 2009 a 2012. Ainda uma ressalva necessária é apresentar o quadro geral do diálogo, que se fazia entre a legislatura e o movimento social organizado que no momento do que chamamos aqui de micro-marco político institucional, era composto por uma Organização Não Governamental (ONG) AMLGBT (Associação Maringaense de Lésbicas, Gays, Bissexuais, Travestis e

\footnotetext{
${ }^{4}$ A seguir apresentamos os nomes e partidos da vereadora e vereadores acima descritos, o que a nosso ver proporciona a quem discute com essa análise apropriar-se do contexto político em que as discussões eram promovidas, a saber: Aparecido Domingos Regini (Zebrão), PP, votos: 2.921. Belino Bravin Filho, PP, votos: 4.265. Carlos Eduardo Sabóia (Dr. Sabóia), PMN, votos: 2.083. Dr. Paulo Soni, PSB, votos 1.551. Dr. Heine Macieira, PP, votos, 3.243. Evandro Júnior, PSDB. Flávio Vicente, PSDB, votos: 4.250. Humberto José Henrique, PT, votos: 3.681. João Alves Correa (John), PMDB. Luiz Carlos Clóvis (Luiz do Postinho), PRP, votos: 1.820. Mário Massao Hossokawa, PMDB, votos: 3.002. Mário Sérgio Verri, PT, votos: 3.077. Marly Martin Silva, PPL, votos: 2.180. Manoel Álvares Sobrinho (Dr. Manoel), PC DO B, votos: 2.791. Wellington Andrade, PRP, votos: 4.862. Disponível em: http://www.cmm.pr.gov.br/?inc=legislatura14. Acesso 01 Jul de 2014.
} 
Transexuais), entidade de caráter misto que buscava atuação das demandas dos direitos humanos dentro do município.

Após a proposta do Dia Municipal de Combate a Homofobia, instituído pela lei $n^{\circ} 8.615 / 2010$ ser institucionalizada, em reunião promovida para alicerçar uma Frente parlamentar municipal que assumisse o debate acerca dos direitos humanos, o BSH foi trazido ao cerne das discussões a partir da seguinte premissa: "V - Direito à Educação: promovendo valores de respeito à paz e a não discriminação por orientação sexual" (BRASIL, 2004, p. 22). Com atenção aos seguintes temas:

- Elaborar diretrizes que orientem os Sistemas de Ensino na implementação de ações que comprovem o respeito ao cidadão e a não discriminação por orientação sexual;

- Fomentar e apoiar curso de formação inicial e continuada de professores na área da sexualidade;

- Formar equipes multidisciplinares para avaliação dos livros didáticos, de modo a eliminar aspectos discriminatórios por orientação sexual e a superação da homofobia;

- $\quad$ Estimular a produção de materiais educativos (filmes, vídeos e publicações) sobre orientação sexual e superação da homofobia;

- Apoiar e divulgar a produção de materiais específicos para a formação de professores;

- Divulgar as informações científicas sobre sexualidade humana;

- Estimular a pesquisa e a difusão de conhecimentos que contribuam para o combate à violência e à discriminação de GLTB;

- Criar o Subcomitê sobre Educação em Direitos Humanos no Ministério da Educação, com a participação do movimento de homossexuais, para acompanhar e avaliar as diretrizes traçadas (BRASIL, 2004, p.23).

Acerca do eixo de formação inicial e continuada de professoras e professores o debate foi estabelecido, sendo assim, a lei $\mathrm{n}^{\circ}$ 11.695/2010 apresenta que: "Art.2 ${ }^{\circ} \mathrm{O}$ programa terá por finalidade promover e facilitar a discussão aprofundada e qualificada da homofobia nas escolas, direcionando para gestores, educadores e estudantes da rede pública municipal de ensino (MARINGÁ, 2010)". Tal artigo é produto da reformulação da lei, $\mathrm{n}^{\circ} 8.728 / 2010$. Pois após aprovação com apenas uma abstenção o projeto de lei $\mathrm{n}^{\circ}$ $8.728 / 2010$ foi vetado (veto $n^{\circ} 813 / 2010$ ) integralmente pelo chefe do poder executivo municipal, no período o prefeito Silvio Barros (PP), vetado sobre as seguintes premissas (reproduziremos em totalidade o texto do veto dirigido ao presidente da Câmara Municipal): 
A presente tem por objetivo levar ao conhecimento de Vossa Excelência e Excelentíssimos senhores vereadores, nos termos no Parágrafo 1 do Artigo 32 da Lei Orgânica Municipal, meu VETO TOTAL ao projeto de leis $n^{\circ} 8728$, de Dr. Manoel Sobrinho e Evandro Junior que cria o Programa Escola sem Homofobia. O texto aprovado estabelece que o Programa irá promover e facilitar a discussão aprofundada e qualificada da homofobia nas escolas, direcionando para gestores, educadores e estudantes da rede pública municipal. Em que pese a $r$, pretensão da inclusa propositura, noto que o projeto aprovado, à evidencia, se traduz em um bis in idem às diversas políticas publicas de defesa de direitos constitucionais. Especificamente, no município de Maringá, temas atuais são fastamente abordados pelos orientadores educacionais nas escolas, inserido também nas discussões sobre bulling (sic), Direitos Humanos, Violência Física e moral, discriminação, bem como através de debates, palestras, folders para pais, alunos e comunidade (MARINGÁ, 2010).

Salientamos que a Artigo 32 da Lei Orgânica do Município de Maringá delibera quando e por que o prefeito deve vetar parcial ou integralmente uma lei, sendo assim, o argumento mais importante seria que já existem leis no plano municipal que contemplam as demandas da lei $\mathrm{n}^{\mathbf{0}} 8728 / 2010$, e a mesma se tornaria um "bis in idem" normativo. Ressaltamos que até então somente duas leis municipais traziam termos como homofobia, combate à violência: uma se expressa na lei do dia municipal de combate à homofobia ${ }^{5}$, a qual possui um caráter não associado a um projeto educacional e a outra a própria lei $\mathrm{n}^{\circ} 8728 / 2010$, alvo do veto total. O que implica em uma confusão, não ingênua, na análise do então chefe do executivo municipal.

Destacamos a seguir outro artigo que julgamos ser importante no que concerne aos empoderamento dos termos e do objetivo da lei $\mathrm{n}^{\mathrm{o}} 11.695 / 2010$, a saber: “Art. 3 Durante a realização do Programa serão abordados, dentre outros, temas relacionados com a manifestação da sexualidade na escola, a discriminação no ambiente escolar, a postura dos educadores e a relação escola-família (MARINGÁ, 2010)”.

Ainda no que concerne ao veto total do prefeito, incluímos aqui alguns dos desdobramentos do texto acima referido dirigido ao legislativo municipal, texto no qual o prefeito argumenta as razões do veto. São elas elaboradas em cinco pontos: 1) "[...] A pretensa inclusão do Programa "Escola Sem Homofobia" surge para discutir um tema já abordado com os educadores e gestores dentro das políticas públicas que objetivam a defesa dos direitos constitucionais [...]" (MARINGÁ, veto nº 813, 2010), sendo que (2)

5 Trata-se da Lei $\mathrm{n}^{\circ} 8.615$ de 11 de Maio de 2010 que Institui no calendário oficial o Dia municipal de Combate à Homofobia. 
"[...] discussões sobre bullings (sic), direitos humanos, violência física e moral, discriminação, são amplamente abordadas pelos orientadores educacionais nas escolas, bem como através de debates, folders para pais, alunos e comunidade [...]" (MARINGÁ, veto $n^{\circ} 813,2010$ ). Ainda no plano da justificativa, ao contrário do que imaginamos ser o exercício da promoção de um debate, no que tange a temas educacionais, esperamos que o mesmo seja feito com auxílio de especialistas da área, estudiosas, professoras e meios institucionalizados que promovam tais discussões. $\mathrm{Na}$ terceira premissa o chefe do executivo municipal alerta que: “[...] (3) Se o objetivo é promover um ensino seguro e receptivo, a superexposição de tais temas, tão carregados de controvérsias e diversidades de opiniões, traria mais preconceito e segregação [...]" (MARINGÁ, veto $\mathrm{n}^{\circ} 813,2010$ ).

Para finalizar, o então prefeito Silvio Barros orienta: “[...] (4) O Poder público Municipal é responsável pela Organização da Educação de nível de ensino de 02 a 10 anos. A tenra idade exige trato familiar bem elaborado sobre a questão [...]" (MARINGÁ, veto $n^{\circ} 813,2010$ ). Entendemos que o trato com a Educação Sexual na Infância e adolescência foi um ponto de embate no debate e na proposição da lei, sendo que em nenhum momento a sugestão de consulta a opiniões da "sociedade" maringaense foi trazida à baila, porém podemos entender, claramente, a que "sociedade" o então chefe do executivo se referia quando observamos o quinto item do veto total que diz que: “[...] (5) Outro fator importante é que entendemos que tal matéria, polêmica e controversa, prescinde de uma ampla discussão e consulta à sociedade organizada, principalmente no âmbito das diversas religiões [...]" (MARINGÁ, veto ${ }^{\circ} 813,2010$ ), grifo nosso.

De ordem prática e com foco na formação de professoras e professores o projeto Escola sem Homofobia destinava verbas específicas para preparação e abordagem do tema, indiferente da "tenra" idade, sabemos com base em amplas pesquisas e literatura normativas em países como Portugal que a Educação Sexual Infantil integra o currículo escolar desde as séries iniciais ${ }^{6}$. Ainda ressaltamos, sem

\footnotetext{
${ }^{6}$ A Lei 120/99 e o Decreto-Lei n. ${ }^{\circ}$ 259/2000 vieram conferir às escolas a obrigatoriedade de incluir no seu projeto educativo o componente de educação sexual e a refleti-lo nos planos de trabalho das turmas. Decreto-Lei n. ${ }^{\circ}$ 259/2000, de 17 de Outubro, Regulamenta a Lei n. ${ }^{\circ} 120 / 99$, de 11 de Agosto (reforça as garantias do direito à saúde reprodutiva), fixando condições de promoção da educação sexual e de acesso dos jovens a cuidados de saúde no âmbito da sexualidade e do planejamento familiar. A título de cumprimento da legislação o governo articulou protocolos com diversas associações: a Associação para o Planejamento da Família, o Movimento de Defesa da Vida e a Fundação Comunidade Contra a Sida. Interessante atentarmos ao âmbito concedido à Lei: [...] O presente diploma visa conceder maior eficácia aos dispositivos legais que garantam a promoção a uma vida sexual e reprodutiva saudável, mais
} 
entrar no mérito da interpretação do que seria uma consulta às diversas religiões que, segundo Maria e Ribeiro (2011), é imprescindível a qualquer proposta em educação sexual que nela contenha instrumentos para o debate acerca da formação cultural da sexualidade e, sobretudo, sobre a condição de papéis sociais e estereótipos de gênero. $\mathrm{O}$ caráter dialógico da educação sexual deve ser fornecido por profissionais capacitados (a consulta às diversas religiões não é facultada como qualificação, pois o mérito moral das sexualidades plurais é altamente atacado dentro de dogmas ortodoxos ou neopentecostais), fazendo com que as inquietações individuais possam ser socializadas.

A autora e o autor destacam os documentos da Assembléia Geral da WAS World Association for Sexology e da Carta de Aveiro, os quais alicerçam a argumentação no tocante a sexualidade, ou melhor, a expressão da sexualidade deve ser um direito fundamental em suas pormenoridades. Concluem que: "Educação inclusiva e integral, que abranja a formação de alunos e professores também em questões de cidadania e direitos humanos, sem que tenha entre seus pontos de debate e estudos, temas envolvendo sexualidade, gênero e diversidade sexual" (MAIA; RIBEIRO, 2011, p.82).

Sendo assim, o caráter inovador da proposta maringaense e sua especificidade vieram a partir do destino de verbas para execução do projeto, a saber: “[...] Art. 5 Para fazer face às despesas iniciais decorrentes da execução desta lei, o Chefe do poder executivo fica autorizado a abrir, no corrente exercício financeiro, um crédito adicional da ordem de $\mathrm{R} \$ 20.000,00$ (vinte mil reais) utilizando para sua cobertura um dos recursos definidos no artigo 43 da Lei no 4320/64 [...]" (MARINGÁ, lei no 11.695, 2010).

Na sessão de 21 de Outubro de 2010, em uma discussão histórica no município, com a comoção da população pelo movimento social organizado AMLGBT, balizado pelo macro-marco política do BSH, a pressão popular fez com que a Câmara municipal derrubasse o veto do prefeito com dez votos contra três ${ }^{7}$, instituindo assim a

gratificante e responsável, consagrando medidas no âmbito da educação sexual, do reforço do acesso ao planejamento familiar e aos métodos contraceptivos, tendo em vista, nomeadamente, a prevenção de gravidezes indesejadas e o combate às doenças sexualmente transmissíveis, designadamente as transmitidas pelo HIV e pelos vírus das hepatites B e C. (PORTUGUAL, Lei 120/99. Reforça as garantias do direito à saúde reprodutiva).

${ }^{7}$ Ressaltamos que os votos favoráveis ao veto foram: Dr. Heine Macieira, líder do prefeito na Câmara municipal, Flávio Vicente, amplo defensor da Igreja Presbiteriana de Maringá e Marly Martins, única vereadora da $14^{\circ}$ Legislatura a qual propôs em 2010 alteração do projeto de Lei $\mathrm{n}^{\circ}$ 5590/2001, o qual deliberava sobre a composição do Conselho Municipal da Mulher de Maringá. Marly Martins defendia que a alínea "h" do inciso II do Artigo $5^{\circ}$ da presente lei, onde a redação constava a composição do conselho por uma vaga de Organização Não-governamental e sociedade civil de mulheres lésbicas e 
lei. Tal condição foi acordada na medida em que o termo "estudantes" foi retirado da lei. Pois, houve consenso em achar que a educação sexual na infância é facultada ao âmbito privado e é mediada pela consulta ampla às diversas opiniões da "sociedade".

\section{Educação sexual e infância: vamos ensiná-los a serem homossexuais?}

Segundo Foucault (1977), nos últimos séculos, ao contrário de uma sistemática repressão sexual, o que ocorreu foi uma produção massiva sobre o sexo. Uma proliferação de discursos de diferentes áreas (medicina, pedagogia, psiquiatria, etc.) incorporaram a sexualidade como objeto de análise. As relações de poder, a regulação, então, passam a se projetar sobre o corpo, sobre o prazer e suas manifestações. Neste contexto, a sexualidade infantil é também alvo dos discursos, principalmente da pedagogia (NUNES; SILVA, 2006).

A escola como Foucault nos apresenta, no século XVIII, apresentava a ausência do discurso sobre sexo. Desde a era vitoriana, a sexualidade foi cuidadosamente confiscada e encerrada por decoros e segredos, apesar de reconhecida e legitimada socialmente "na seriedade da função de reproduzir" (FOUCAULT 1977, p. 9-10). Atos e palavras sobre o sexo passaram a ser regulados, expulsos, negados e reduzidos ao silêncio por gerações, que justificam essa interdição pela crença de que "as crianças [...] não têm sexo "(FOUCAULT 1977, p. 10-11).

A sexualidade infantil apresenta-se na escola como um grande desafio pela transformação que promove na prática educativa, ao desvelar os ocultamentos e silenciamentos acerca da temática (NUNES; SILVA, 2006). Expressa por crenças, atitudes, valores, papéis e relacionamentos é produto de um trabalho permanente de ocultação, de dissimulação ou de mistificação na escola, um reflexo do que se produz da mesma forma na sociedade. Entendendo a sexualidade como construção social, histórica e política, relacionada ao poder e à regulação, com formas e variações impossíveis de serem explanadas sem examinar e explicar seu contexto formativo (FOUCAULT, 1977), sendo assim, pensamos em um trabalho investigativo que focaliza o educador e sua experiência, acerca da sexualidade infantil, com a criança e seu corpo em

bissexuais, fosse então substituída pelo seguinte texto: "uma representante das entidades de recuperação de prostitutas e lésbicas". A vereadora de forte vínculo eleitoral com igrejas neopentecostais, após mobilização popular da AMLGBT retirou o projeto da pauta de votação na Câmara Municipal. 
desenvolvimento, num programa pedagógico tal como assevera-nos Maia e Ribeiro (2011).

O processo de escolarização dos corpos, esclarece Louro (2001, p.21), educa a sexualidade das crianças por meio de pedagogias, muitas vezes sutis e discretas, nem sempre explícitas ou intencionais, mas não por isso menos eficientes e duradouras. Segundo Louro (2001, p.19), existem poucos os estudos que tentam dar conta da construção das identidades sexuais na infância ${ }^{8}$. As escolas costumam adotar o corpo como ponto de partida para educar as crianças e, como consequência, produzir uma sexualidade "normal"- masculina ou feminina.

Concluímos que no âmbito da discussão do projeto de lei, houve inferências diversas sobre a condição da educação sexual na infância, porém em nenhum momento o poder público preocupou-se em debater com educadoras, diretoras, gestoras a possibilidade do projeto. É importante lembrar a ressalva feita pelo chefe do executivo municipal na consulta à sociedade organizada, principalmente no âmbito das diversas religiões [...]" (MARINGÁ, veto $\mathrm{n}^{\circ}$ 813, 2010), grifo nosso. A sociedade civil organizada apresentou a demanda, promoveu a discussão e junto ao vereador Luiz do postinho, endossou o projeto de lei. O entrave político causado pela reverberação do projeto; fez com que no dia da derrubada do veto, alhures de qualquer posição acadêmica ou pedagógica educacional mais séria, a Ordem do Pastores de Maringá ocupasse quase que cinquenta por cento da plenária da Câmara municipal, realçando questões peculiares entre as demandas da cidadania LGBT no Brasil, no que circunscreve às políticas públicas afirmativas e os fundamentalismos religiosos.

\section{Participação política e fundamentalismos: 10 anos do bsh entre tentativas e erros}

Para esse debate trazemos Mello; Avelar e Maroja, em artigo de (2012) na Revista Sociedade e Estado quando nos apresentam que:

Em particular, no que diz respeito às políticas públicas no campo da sexualidade, convém ainda destacar que elas são permeadas de

\footnotetext{
${ }^{8}$ Afirmamos que a máxima não é a mesma quando pensamos na produção sobre como, por que e quais os meios de se trabalhar com a educação sexual na infância e séries iniciais, o que trazemos para debate aqui é a noção, pueril, de que podemos condicionar ora à normalidade, homem, mulher, heterossexuais ou à "anormalidade" homem, mulher, lésbicas, gays ou transexuais. Eis o que Louro (2001) nos apresentaram em suas discussões.
} 
peculiaridades, já que o ponto de partida para sua formulação e implementação é basicamente a necessidade de mudança de crenças, valores e tradições há muito prevalecentes no imaginário coletivo. $\mathrm{O}$ projeto de uma sociedade sem sexismo, machismo e homofobia, capaz de incluir pessoas que hoje são marginalizadas e perseguidas por não se conformarem ao pensamento majoritário, tem também suas próprias contradições, sendo uma das principais o risco de a assimilação implicar a própria descaracterização ou desintegração identitária das pessoas e grupos LGBT. Ou seja, essa "nova sociedade" também exigiria de suas/seus integrantes a conformação a modelos de homossexualidade, travestilidade e transexualidade socialmente hegemônicos, mantendo à margem todas/os as/os que se recusarem a incorporar as personas sexuais aceitáveis, independentemente de orientação sexual e identidade de gênero: as/os que se casam e têm filhas/os, as/os que se conformam aos binarismos de gênero e as/os que são adeptas/os de um erotismo familista. Somese a isso o fato de que a população LGBT ainda não gera um tipo de solidariedade similar à que caracteriza grupos como idosas/os, crianças e adolescentes, por exemplo, que despertam uma cumplicidade social generalizada com seus problemas e dificuldades, o que os torna beneficiários potenciais legítimos de políticas públicas. Talvez por essa razão que se fundamenta na homofobia prevalecente em larga escala, a resistência ainda seja tão acentuada quando o assunto são políticas públicas envolvendo sexualidade e, mais especificamente, sexualidade não heterossexual (MELLO; AVELAR; MAROJA, 2012, p.294-195).

Sendo assim, a discussão que essa análise se propôs é reviver um processo de participação civil, que influenciada pelo Brasil Sem Homofobia (BSH), entendido aqui como um macro-marco político institucional, mesmo com as ressalvas e críticas, proporcionou um debate em esferas das micro-políticas. Porém, como podemos ver nas palavras de Mello; Avelar e Maroja (2012), a resistência localizada, programada e objetiva de fundamentalismo (principalmente religiosos, classistas, racistas e sexistas) impele o movimento LGBT de participação e monitoração efetivas de políticas públicas afirmativas. Pois, não adianta dizer que se trabalha a discriminação e não a homo/les/trans/bi fobias, que se trabalha na escola com direitos humanos e nada se comenta sobre opressões às identidades de gênero ou à transexualidade. É farta a possibilidade de interlocuções entre a infância e a sexualidade, tão logo a educação sexual infantil. Outrora precisássemos recorrer a cânones como Freud, Rousseau ou Piaget, pois seria inesgotável e ultrapassaria o objetivo de nossa análise.

Sobre a lei $n^{\circ} 11.695 / 2010$ que alterou a lei ${ }^{\circ} 8.728 / 2010$, em 2011, um ano após sua dotação orçamentária e institucionalização, a Secretária Municipal de Educação ao manifestar-se no parecer $n^{\circ} 028 / 11$ em resposta ao processo $n^{\circ}$ 
45197/2011, Ofício 877/2011, o qual pedia informações sobre a implementação da lei, responde da seguinte maneira:

a) O tema da sexualidade vem sendo trabalhado, de acordo com a necessidade de cada unidade escolar, a discriminação no ambiente escolar é trabalhada na reunião de pais, com representantes das turmas, com alunos em pequenos grupos e individualmente;

b) Assevera que as atividades estão sendo desenvolvidas sob orientação da Orientadora Educacional, cita exemplo como: Reunião para a Paz, que aborda as diferenças e os preconceitos. Reunião com as famílias sobre direitos e deveres, reuniões com pais sobre bullying;

c) No tocante às alunas e alunos, o parecer diz que há reflexões em pequenos grupos sobre, bullying, sexualidade e preconceito, segundo a demanda apresentada nas unidades escolares. Que há trabalhos com representantes de turmas sobre educação para paz, que houve panfletagem sobre Bullying na Escola Municipal José Anicetto no mês de Agosto de 2011;

d) Panfletagem sobre Bullying na Escola Silvino Dias durante o domingo de "escola aberta" e mostra de cinema com representantes das turmas analisando temas relacionados à educação para paz;

e) Acerca das equipes pedagógicas o documento relata que: todas as orientadoras educacionais participaram de seminários de educação para paz e segurança para vida de 2009 a 2011. Que a equipe pedagógica participou da formação da Jornada pedagógica cujo tema foi violência.

f) Implementou parceria com a Secretaria de Assistência Social (SASC) no tocante aos casos de violência e negligência familiar;

g) Elaboração de cartilhas, pelas alunas e alunos sobre drogas e Bullying;

h) No tocante à relação escola e famílias o parecer afirma que há reuniões bimestrais, mostras culturais e atendimentos individuais.

O documento foi assinado pela então Secretária de Educação Professora Edith

Dias de Carvalho em 18 de agosto de 2011. Essa é a última comunicação formal sobre a lei $n^{\circ} 11.695 / 2010$ que esbarra no que Mello, Avelar e Maroja (2012) nos apresenta:

A fim de que planos e programas se tornem instrumentos efetivos de promoção de cidadania e direitos humanos, é fundamental que se viabilize maior interlocução entre formuladoras/es e executoras/es de ações. Sem isso, corre-se o risco de uma enorme distância entre o que se propõe executar e o que de fato é executado. O diálogo entre gestoras/es dos níveis federal, estaduais e municipais talvez seja o principal desafio a ser alcançado, já que, muitas vezes, disputas partidárias, ideológicas ou simplesmente de prestígio dificultam a execução de um trabalho coordenado, envolvendo distintas/os atrizes/atores sociais (MELLO; AVELAR; MAROJA, 2012, p.309). 
Permitimo-nos repetir o acima já dito pra reforçarmos que o processo de escolarização dos corpos como nos apresentou Louro (2001, p.21), educa a sexualidade das crianças por meio de pedagogias, muitas vezes sutis e discretas, nem sempre explícitas ou intencionais, mas, não por isso, menos eficientes e duradouras. Então, devemos investir nas condições explícitas de combate a homo/les/trans/bi fobias, à desigualdade de gênero, ao sexismo, ao machismo, dentre tantas outras opressões que se interseccionam na sutileza discreta do ambiente escolar, sutilezas muitas vezes levadas por nós professoras e professores e não combatidas com eficiência e convicção.

\section{REFERÊNCIAS}

BRASIL, Conselho Nacional de Combate à Discriminação/ Ministério da Saúde. Brasil sem Homofobia: Programa de combate à violência e à discriminação contra GLBT e promoção da cidadania homossexual. Brasília: Ministério da Saúde, 2004.

FACCHINI, R. Sopa de Letrinhas?: Movimento homossexual e produção de identidades coletivas nos anos de 1990. Rio de Janeiro: Garamond, 2005.

FOUCAULT, M. História da sexualidade I: a vontade de saber. Rio de Janeiro: Edições Graal, 1977.

LOURO, G. L. Pedagogias da Sexualidade. In: (org.). O Corpo educado: pedagogias da sexualidade. Belo Horizonte: Autêntica, 2001.

MAIA, A. C. B; RIBEIRO, P. R. M. Educação sexual: princípios para ação. In: Doxa: Revista Brasileira de Psicologia e Educação. Universidade Estadual Paulista, Faculdade de Ciências e Letras de Araraquara. Vol.14-(2010) Araraquara: UNESP/FCLAR-Laboratório Editorial, 2011.

MARINGÁ. Lei 11.695 de 05 de junho de 2010. Institui o Projeto Escola sem Homofobia. Disponível em: 〈http://www.cmm.pr.gov.br>. Acesso em 03 de jul de 2014.

MARINGÁ. Lei Orgânica do Município. Disponível em: http://www.cmm.pr.gov.br. Acesso em 03 de jul de 2014.

MARINGÁ. Lei 8615 de 11 de maio de 2010. Institui o Dia municipal de combate a homofobia. Disponível em: <http://www.cmm.pr.gov.br>. Acesso em 03 de jul de 2014.

MARINGÁ. Mensagem n.197/2010. Veto n.813 de 27 de setembro de 2010. 
MARINGÁ, Secretaria de Educação. Parecer n.028/2011 (SEDUC) de 24 de Agosto de 2011.

MELLO, L; AVELAR, B. R; MAROJA, D. Por onde andam as políticas públicas para a população LGBT no Brasil. Revista Sociedade e Estado - Volume 27 Número 2 -

maio/agosto 2012. Disponível em: 〈http://www.scielo.br/pdf/se/v27n2/a05v27n2.pdf〉. Acesso 03 de jul de 2014.

NUNES, C; SILVA, E. A educação sexual da criança: subsídios teóricos e propostas práticas para uma abordagem da sexualidade para além da transversalidade. Campinas, SP: Autores Associados, 2006.

PORTUGAL, Decreto-Lei n. ${ }^{\mathbf{2}} \mathbf{2 5 9} / \mathbf{2 0 0 0}$, de 17 de Outubro, Regulamenta a Lei n. ${ }^{\mathbf{o}}$ 120/99, de 11 de Agosto (reforça as garantias do direito à saúde reprodutiva), fixando condições de promoção da educação sexual e de acesso dos jovens a cuidados de saúde no âmbito da sexualidade e do planeamento familiar (JusNet 124/2000).

PORTUGAL, Lei n. ${ }^{\circ}$ 120/99, de 11 de Agosto, Reforça as garantias do direito à saúde reprodutiva. (JusNet 639/1999).

\section{Como referenciar este artigo}

SANTOS, Franciele Monique Scopetc dos.; MAIA, Ana Cláudia Bortolozzi. Diásporas e aproximações entre educação sexual nas séries iniciais e enfrentamento ao preconceito: discussões sobre a lei municipal "escola sem homofobia" de Maringá. Revista Ibero-Americana de Estudos em Educação, Araraquara/SP, v. 11, n. 3, p.1281-1293, 2016. Disponível em: 〈https://dx.doi.org/10.21723/riaee.v11.n3.7153〉. EISSN: 1982-5587.

Submetido em: 08/08/2014

Aprovação final em: 11/07/2016 